\title{
Temperature- and Pressure-Induced Polyamorphic Transitions in AuCuSi Alloy
}

\author{
Salman Ali Khan, ${ }^{\dagger}$ Xiao-Dong Wang, ${ }^{*}{ }^{\dagger}$ Azkar Saeed Ahmad, ${ }^{\dagger}$ Qing-Ping Cao, ${ }^{\dagger}$ Dong-Xian Zhang, ${ }^{\dagger,}$ \\ Yun-Zhang Fang, ${ }^{\S}$ Hao Wang, $\|$ and Jian-Zhong Jiang ${ }^{*}+{ }^{\dagger}$
}

${ }^{\dagger}$ International Center for New-Structured Materials (ICNSM), State Key Laboratory of Silicon Materials, and School of Materials Science and Engineering, and ${ }^{\ddagger}$ State Key Laboratory of Modern Optical Instrumentation, Zhejiang University, Hangzhou 310027, People's Republic of China

${ }^{\S}$ Institute of Condensed Matter Physics, Zhejiang Normal University, Jinhua 321004, People's Republic of China

"Institute of Nanosurface Science and Engineering, Shenzhen University, Shenzhen 518060, People's Republic of China

Supporting Information

ABSTRACT: Temperature-induced liquid-liquid phase transition (LLPT) and pressureinduced amorphous-amorphous phase transition (AAPT) have never been simultaneously reported in any single metallic system. In an $\mathrm{Au}_{55} \mathrm{Cu}_{25} \mathrm{Si}_{20}$ alloy, however, we discovered a temperature-induced LLPT by detecting "reversible $\lambda$-anomalies" of the thermal expansion coefficient between two liquid states at ambient pressure, while a pressure-induced AAPT in $\mathrm{Au}_{55} \mathrm{Cu}_{25} \mathrm{Si}_{20}$ metallic glass (MG) occurs upon compression at ambient temperature. Both LLPT and AAPT are reversible with a hysteresis in temperature and pressure, respectively. Using molecular dynamics simulations and synchrotron $\mathrm{X}$-ray techniques, we elucidate structural differences in both low- and high-pressure $\mathrm{Au}_{55} \mathrm{Cu}_{25} \mathrm{Si}_{20}$ MG phases and low- and hightemperature $\mathrm{Au}_{55} \mathrm{Cu}_{25} \mathrm{Si}_{20}$ liquid phases. Electronic transfer between $\mathrm{Si}$ and $\mathrm{Au}$ or/and $\mathrm{Cu}$ atoms occurs in both temperature-induced LLPT and pressure-induced AAPT in the $\mathrm{Au}_{55} \mathrm{Cu}_{25} \mathrm{Si}_{20}$ alloy.

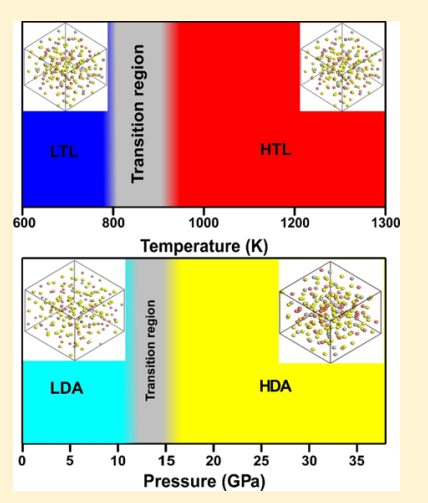

\section{INTRODUCTION}

Phase transitions in materials are the subject of great interest because of their cardinal essentialness in earth and planetary sciences, physics, chemistry, and materials science multidisciplines. ${ }^{1-4}$ The polyamorphic transition induced by temperature and/or pressure, defined as a transition between two different disordered phases (without long range translation and orientation symmetries and with the same composition) in disordered materials, for example, liquids and amorphous materials, is often more complex as compared to the polymorphic transition in crystalline materials. ${ }^{5-8}$ The temperature-induced liquid-liquid phase transitions (LLPT) have been studied both experimentally and theoretically for a few non-metallic substances, for example, supercooled liquid $\mathrm{Si}^{9-11} \mathrm{P},{ }^{12,13} \mathrm{C},{ }^{14} \mathrm{SiO}_{2},{ }^{15,16} \mathrm{Al}_{2} \mathrm{O}_{3}-\mathrm{Y}_{2} \mathrm{O}_{3},{ }^{17,18} \mathrm{H}_{2} \mathrm{O},{ }^{1,19-21}$ and triphenyl phosphite, ${ }^{22}$ while the pressure-induced amorphous-amorphous phase transitions (AAPT) have also been reported in tetrahedral 4 and 5 coordinated nonmetallic glasses with directional bonding and an open local environment. ${ }^{23-27}$ Simultaneously, temperature- and pressure-induced polyamorphic transitions in metallic systems have not been reported yet. Here, we report unambiguous experimental evidence for temperature-induced LLPT and pressure-induced AAPT in one alloy of a composition of $\mathrm{Au}_{55} \mathrm{Cu}_{25} \mathrm{Si}_{20}$. The temperature-induced LLPT occurs in a temperature range of $700-900 \mathrm{~K}$ at ambient pressure, characterized by the "reversible $\lambda$-anomalies" of thermal expansion coefficient between two liquid phases detected from in situ hightemperature X-ray diffraction (XRD), a broad dip in heat flow and a peak in heat capacity from differential scanning calorimetric (DSC). Subsequently, different structures and thermal parameters are observed for the solid $\mathrm{Au}_{55} \mathrm{Cu}_{25} \mathrm{Si}_{20}$ samples quenched from low- and high-temperature $\mathrm{Au}_{55} \mathrm{Cu}_{25} \mathrm{Si}_{20}$ liquid phases. Furthermore, the pressure-induced AAPT in the $\mathrm{Au}_{55} \mathrm{Cu}_{25} \mathrm{Si}_{20}$ metallic glass (MG) occurs upon compression from $\sim 13.1$ to $\sim 15.8 \mathrm{GPa}$ at ambient temperature. Both LLPT and AAPT are reversible. Our ab initio molecular dynamics (AIMD) simulations reproduce the experiment results by revealing the polyamorphic phase transitions in the $\mathrm{Au}_{55} \mathrm{Cu}_{25} \mathrm{Si}_{20}$ alloy. This finding will trigger more studies in deeply understanding phase transitions in disordered materials, especially metallic systems.

Concerning metallic liquids, a possible metal-nonmetal transition in liquid $\mathrm{Na}^{28}$ a tetrahedral clustering of nearest neighbors in liquid $\mathrm{Li}$ at pressure $150 \mathrm{GPa}^{29}$ were proposed. For several monoatomic metallic liquids (i.e., $\mathrm{Al}, \mathrm{Zn}, \mathrm{Sn}$ and In), Lou et al. ${ }^{30}$ found that the average interatomic distance between the center atom and those on the first shell contracts with increasing temperature. Temperature-induced LLPTs above their liquidus temperatures were implied in $\mathrm{La}_{50} \mathrm{Al}_{35} \mathrm{Ni}_{15}$

Received: May 30, 2019

Revised: July 25, 2019

Published: August 7, 2019 
alloy by ${ }^{27} \mathrm{Al}$ nuclear magnetic resonance measurements, ${ }^{31}$ in $\mathrm{Rb}^{32} \mathrm{Ce}{ }^{33}$ and $\mathrm{Ga}^{34}$ by high-temperature synchrotron radiation-based XRD experiments and AIMD simulations. A LLPT in the undercooled liquid region was indicated in $\mathrm{Zr}_{41.2} \mathrm{Ti}_{13.8} \mathrm{Cu}_{12.5} \mathrm{Ni}_{10} \mathrm{Be}_{22.5}$ alloy, ${ }^{35}$ which was accompanied by changes in the local atomic structure and viscosity but without a detectable density anomaly. LLPTs are sometimes associated with a dynamical crossover with changes in the kinetic fragility. ${ }^{15,35-38}$ When observed upon cooling, the liquid evolves from a high-temperature fragile phase with a steep temperature dependence of viscosity and structural relaxation time to a strong phase less affected by temperature changes. Metallic glasses, exhibiting many excellent properties, have attracted considerable attention, which are often densely compacted. Although pressure-induced AAPTs were recently reported in a few f-electron containing (Ce-, $\mathrm{Pr}$-, Yd-based) $\mathrm{MGs}^{39-48}$ and one case in CaAl MGs, ${ }^{49,50}$ it is still challenging to provide more evidence for pressure-induced AAPT in non-felectron containing MGs. ${ }^{51-53}$

\section{METHODS}

$\mathrm{Au}_{55} \mathrm{Cu}_{25} \mathrm{Si}_{20}$ alloy ingots were prepared by arc melting constituent elements with purity higher than 99.99 at. \% in a $\mathrm{Zr}$-gettered argon atmosphere. Each ingot was re-melted four times to improve the chemical homogeneity. The liquidus temperature of $\mathrm{Au}_{55} \mathrm{Cu}_{25} \mathrm{Si}_{20}$ alloy is $654 \mathrm{~K}$. Ribbon $\mathrm{Au}_{55} \mathrm{Cu}_{25} \mathrm{Si}_{20}$ alloys were solidified in a melt-spun facility from the liquid at two temperatures, one above $900 \mathrm{~K}$ and the other below $750 \mathrm{~K}$, which were measured by using a pyrometer with a uncertainty of about $30-50 \mathrm{~K}$. $\mathrm{Au}_{55} \mathrm{Cu}_{25} \mathrm{Si}_{20}$ alloy ingot was put into narrow tubes with diameter of $0.7 \mathrm{~mm}$ and thickness around $0.01 \mathrm{~mm}$. To make the tubes completely evacuated, vacuum was created up to $8.6 \times 10^{-4} \mathrm{~Pa}$ and directly sealed. A heating furnace with the heating rate of 10 $\mathrm{K} / \mathrm{min}$ was used to heat the sealed tubes. During heating, the $\mathrm{XRD}$ patterns were gathered, with the beam dimension of 0.3 $\times 0.3 \mathrm{~mm}^{2}$ and wavelength of $0.117 \AA$ via a PerkinElmer 1621 Si detector having $2048 \times 2048$ pixels and $200 \times 200 \mu \mathrm{m}^{2}$ pixel size. The experiment was performed at sector 11-ID-C of advanced photon source (APS), Argonne National Laboratory, USA. The distance from the detector to the sample was $400.893 \mathrm{~mm}$ and for the normalization, total incident flux was recorded. For each XRD pattern, 0.5 acquisition time was set, and to get precise results, $10 \mathrm{XRD}$ patterns were added to get a single XRD file. After measurements, the sample still retained metallic shinning behavior. For proper removal of background from original data, the XRD pattern of an empty tube with same thickness and diameter was recorded. Diffraction intensity $I(q)$ patterns were incorporated under the software package FIT2D ${ }^{54}$ after properly subtracting the background. Afterwards by using PDFgetX3, ${ }^{55}$ we have taken out the contribution of the self-absorption, polarization, fluorescence absorption and Compton scattering from the resultant data, to obtain the total structure factor $S(q)$.

In situ high-temperature small-angle X-ray scattering (SAXS) experiments were also performed at APS, beamline sector (1-ID). The round process of heating to $1174 \mathrm{~K}$ and then cooling to $673 \mathrm{~K}$ was carried out at a rate of $10 \mathrm{~K} / \mathrm{min}$. The beam size was about $50 \mu \mathrm{m}$ vertically and about $200 \mu \mathrm{m}$ horizontally with an energy of about $110 \mathrm{keV}$. The SAXS signals in transmission mode were recorded by a PIXIRAD CdTe photon counting detector located about $6 \mathrm{~m}$ away from the sample. The exposure time was $1 \mathrm{~s}$, and 10 images were summed for each data set (about $1.7 \mathrm{~K}$ temperature range). The direct-beam X-ray intensities before and after the specimen were recorded, by which the transmission could be calculated. The dark- and bright-field background subtraction and absolute scaling to a glassy carbon standard were also corrected to get the absolute SAXS intensity of the sample at each temperature.

The heat flow and heat capacity $C_{p}(T)$ data of liquid $\mathrm{Au}_{55} \mathrm{Cu}_{25} \mathrm{Si}_{20}$ alloy using aluminum pans were determined by DSC in PerkinElmer DSC-7 in a high-purity Ar atmosphere. Both heating and cooling heat flow measurements were conducted using a heating rate of $20 \mathrm{~K} / \mathrm{min}$, while for heat capacity measurements, a $5 \mathrm{~K}$ step heating method was used, with a heating rate of $5 \mathrm{~K} / \mathrm{min}$ and isothermal holding time (300 s) after each interval. The heat capacity of liquid $\mathrm{Au}_{55} \mathrm{Cu}_{25} \mathrm{Si}_{20}$ alloy was determined by comparing the alloy heat flow with reference to standard sapphire and empty aluminum pan by using the equation described in literature. ${ }^{56}$

A Mao-Bell-type diamond anvil cell (DAC) with a culet 300 $\mu \mathrm{m}$ in diameter was used for $\mathrm{Au}_{55} \mathrm{Cu}_{25} \mathrm{Si}_{20}{ }^{57} \mathrm{MG}$ for the in situ high-pressure angle-dispersive $\mathrm{XRD}$ experiment. The sample chamber was about $\sim 100 \mu \mathrm{m}$ in diameter drilled in a preindented T301 stainless steel gasket. The sample was loaded into the chamber along with ruby to perform the pressure calibration. The helium was used as a pressure-transmitting medium. The in situ high-pressure XRD experiments was conducted at beamline P02.2 of PETRAIII with the wavelength of $0.2952 \AA$.

The first-principles simulations for $\mathrm{Au}_{55} \mathrm{Cu}_{25} \mathrm{Si}_{20}$ liquid were executed by employing the Vienna ab initio Simulation package (VASP), ${ }^{58}$ based on the density functional theory. The canonical NVT ensemble combined with a Nosé-Hoover thermostat to control the temperature ${ }^{59,60}$ is used for current work. The general gradient approximation in the form described by Perdew-Burke-Ernzerhof is employed for the exchange-correlation energy functional. By using a time step of $3 \mathrm{fs}$, Newton's equations of motion was extracted via the velocity Verlet algorithm. Only the $\Gamma$ point was utilized to sample the Brillouin zone of the supercell. The cubic box used contains 200 atoms with periodic boundary conditions. The system was heated and equilibrated at $2000 \mathrm{~K}$ to remove the crystalline symmetry, for 8000 AIMD steps, from the initial configurations, and then quenched stepwise to 1500, 1400, $1300,1200,1100,1150,1000,900,850,800,750,700$, and $600 \mathrm{~K}$ with a cooling rate of $0.1 \mathrm{~K} / \mathrm{step}$. At each temperature, the equilibrium volume was maintained during AIMD simulations by keeping the internal pressure approximately zero within about $\sim 1.0 \mathrm{kbar}$. After adopting the required internal pressure accuracy, the data were run for further 8000 steps for achieving the equilibrium state. The last 2000 steps were used for statistical analyses.

The AIMD simulations for the pressure effect on $\mathrm{Au}_{55} \mathrm{Cu}_{25} \mathrm{Si}_{20}$ MG were also executed by using the Vienna $\mathrm{ab}$ initio Simulation package (VASP) by following the same conditions and box size as mentioned above. However, the systems were melted and equilibrated at $2000 \mathrm{~K}$ for 8000 steps to remove the memory of the initial configurations and then quenched into steps down to $300 \mathrm{~K}$ with a cooling rate of 0.1 $\mathrm{K} /$ step. The equilibrium volume was established at $300 \mathrm{~K}$ by keeping the internal pressure approximately zero (about \pm 1.0 kbar). Similarly, at ambient temperature, pressure was applied by uniformly decreasing the volume of the box. At each pressure point, after getting the required pressure value, the 
box was relaxed further for 10000 steps to achieve an equilibrium state. The last 2000 steps data were used for statistical analyses.

\section{RESULTS AND DISCUSSION}

Figure 1 illustrates total structure factors $S(q)$ of an $\mathrm{Au}_{55} \mathrm{Cu}_{25} \mathrm{Si}_{20}$ liquid alloy extracted from in situ high-energy
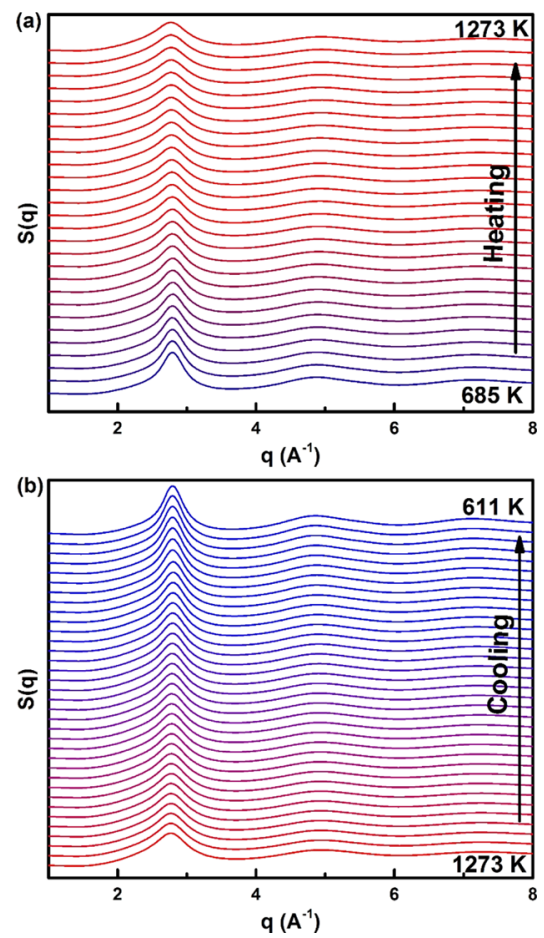

Figure 1. In situ high-energy high-temperature synchrotron XRD patterns. Total structure factors $S(q)$ at various temperatures obtained from in situ high-energy synchrotron XRD measurements for liquid $\mathrm{Au}_{55} \mathrm{Cu}_{25} \mathrm{Si}_{20}$ alloy, (a) during heating from 685 to $1273 \mathrm{~K}$ and (b) during cooling from 1273 to $611 \mathrm{~K}$.

XRD measurements over the entire heating (685-1273 K) and cooling $(1273-611 \mathrm{~K})$ cycle. Figure 2a shows the first peak position, $q_{1}$, of $S(q)$ as a function of temperature during the entire heating and cooling cycle. During heating, the first peak position shifts to small $q$ values. A deviation from the linearity in the temperature dependence of the peak position occurs at around 770 to $900 \mathrm{~K}$. After that, $q_{1}$ shifts linearly again to low $q$ values with increasing temperature up to $1273 \mathrm{~K}$. Upon subsequent cooling, $q_{1}$ first follows the heating trace until a sudden decrease at around $770 \mathrm{~K}$, and then increases linearly again below about $700 \mathrm{~K}$. The slopes of $q_{1}$ versus $T$ in the temperature range below $770 \mathrm{~K}$ and above $900 \mathrm{~K}$ during heating are estimated to be $-2.62(3) \times 10^{-5}$ and $-8.13(3) \times$ $10^{-5}(\AA \mathrm{K})^{-1}$, respectively, while during cooling, they are $-2.66(3) \times 10^{-5}(\AA \mathrm{K})^{-1}$ below $700 \mathrm{~K}$ and $-8.17(3) \times 10^{-5}$ $(\AA \mathrm{K})^{-1}$ above $770 \mathrm{~K}$, revealing that the slope change from the low-temperature range to the high-temperature range in liquid $\mathrm{Au}_{55} \mathrm{Cu}_{25} \mathrm{Si}_{20}$ alloy during heating is reversible during cooling within the experimental uncertainty, despite a slight shift of the temperature range. The reproducible relationship between $q_{1}$ and $T$ during heating and cooling demonstrates that a temperature-induced LLPT likely exists in the liquid $\mathrm{Au}_{55} \mathrm{Cu}_{25} \mathrm{Si}_{20}$ alloy. To quantitatively evaluate the thermal expansion for liquid $\mathrm{Au}_{55} \mathrm{Cu}_{25} \mathrm{Si}_{20}$ alloy, the method, that is, the

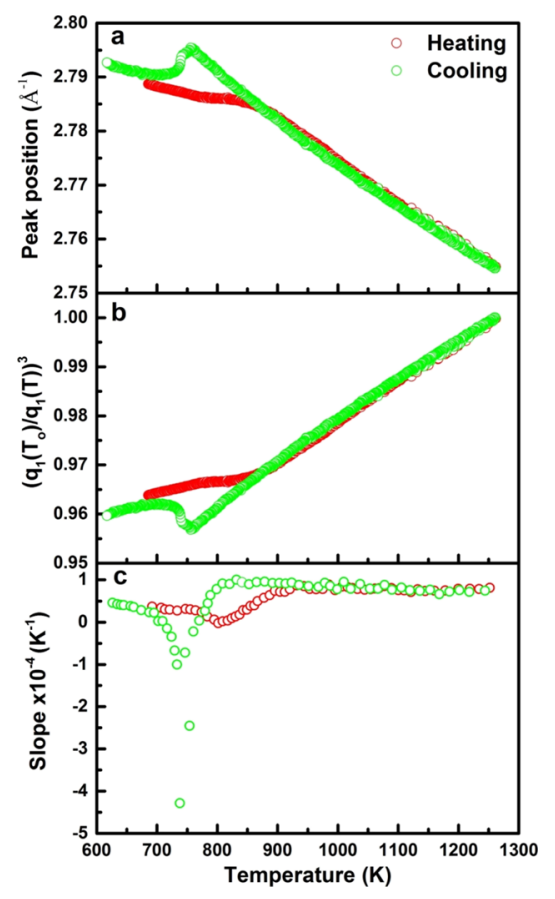

Figure 2. Structural changes. Temperature-dependent structural changes during entire heating and cooling cycle for liquid $\mathrm{Au}_{55} \mathrm{Cu}_{25} \mathrm{Si}_{20}$ alloy, (a) first peak position of $S(q)$, (b) parameter of $\left(q_{1}\left(T_{\mathrm{o}}\right) / q_{1}(T)\right)^{3}$, and $(\mathrm{c})$ slopes of the $\left(q_{1}\left(T_{\mathrm{o}}\right) / q_{1}(T)\right)^{3}$ vs $T$.

ratio of $\left(q_{1}\left(T_{0}\right) / q_{1}(T)\right)^{3}$ is approximately proportional to the relative change of sample volume for glassy alloys and also metallic liquids at various temperatures, although the proportional coefficients might be slightly different between glassy alloys and metallic liquids, ${ }^{61-66}$ was applied, where $T_{0}$ is a reference temperature of $1273 \mathrm{~K}$ used here in Figure $2 \mathrm{~b}$. Figure $2 \mathrm{c}$ shows the volume thermal expansion coefficient for liquid $\mathrm{Au}_{55} \mathrm{Cu}_{25} \mathrm{Si}_{20}$ alloy estimated from the derivative of $\left(q_{1}\left(T_{0}\right) /\right.$ $\left.q_{1}(T)\right)^{3}$ versus $T$ (slope). Even if various power law values from 2 to 3 were used in Supporting Information Figure S1, the same conclusion can be deduced as in Figure $2 \mathrm{~b}, \mathrm{c}$. It is demonstrated that the volume thermal expansion coefficient of liquid $\mathrm{Au}_{55} \mathrm{Cu}_{25} \mathrm{Si}_{20}$ alloy is about $3.7 \times 10^{-5} \mathrm{~K}^{-1}$ below $770 \mathrm{~K}$ during heating and below $700 \mathrm{~K}$ during cooling, and changes to about $7.5 \times 10^{-5} \mathrm{~K}^{-1}$ above $900 \mathrm{~K}$ during heating and above $800 \mathrm{~K}$ during cooling, exhibiting a reversible " $\lambda$-anomalies" in the temperature range of $700-800 \mathrm{~K}$ during cooling and a relatively wide temperature range of $770-900 \mathrm{~K}$ during heating. Figure S2 describes the full width at half-maximum (fwhm) of the first peak of $S(q)$ as a function of temperature during heating and cooling cycles. A deviation from the linearity in the temperature dependence of the fwhm also occurs at around 770 to $900 \mathrm{~K}$ during heating, while upon subsequent cooling, the heating trace until a sudden deviation at around $770 \mathrm{~K}$ is first followed. To further examine the " $\lambda$ anomalies" in volume thermal expansion coefficients, the temperature-dependent heat flow during the entire heating and cooling cycle and specific heat capacity during heating of liquid $\mathrm{Au}_{55} \mathrm{Cu}_{25} \mathrm{Si}_{20}$ alloy are measured in Figure 3. After the melting process at around $630 \mathrm{~K}$, the heat flow of liquid $\mathrm{Au}_{55} \mathrm{Cu}_{25} \mathrm{Si}_{20}$ alloy exhibits a broad dip at around $823 \mathrm{~K}$ during heating and around $740 \mathrm{~K}$ during cooling. The temperatures for the broad dip during heating and cooling remain almost unchanged using various heating rates of 5,10 , and $20 \mathrm{~K} / \mathrm{min}$ in Figure 4 . The 


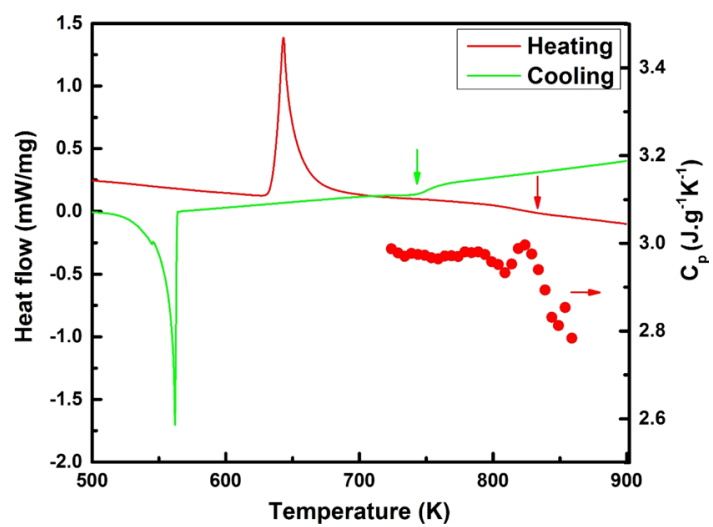

Figure 3. DSC measurements. Heat flow for $\mathrm{Au}_{55} \mathrm{Cu}_{25} \mathrm{Si}_{20}$ alloy during heating (red line) from 500 to $930 \mathrm{~K}$ and during cooling (green line) from 930 to $500 \mathrm{~K}$ using a rate of $20 \mathrm{~K} / \mathrm{min}$ in a highpurity Ar atmosphere by PerkinElmer DSC-7. The endothermal peak at $630 \mathrm{~K}$ during heating and the exothermal peak at $560 \mathrm{~K}$ during cooling are melting and solidification reactions, respectively. The specific heat capacity data (circles) $C_{p}$ as a function of temperature for liquid $\mathrm{Au}_{55} \mathrm{Cu}_{25} \mathrm{Si}_{20}$ alloy during heating from 717 to $852 \mathrm{~K}$ using a 5 K-step heating mode, a heating rate of $5 \mathrm{~K} / \mathrm{min}$ and isothermal holding time (300 s) after each interval measured in a high-purity $\mathrm{Ar}$ atmosphere by PerkinElmer DSC-7.

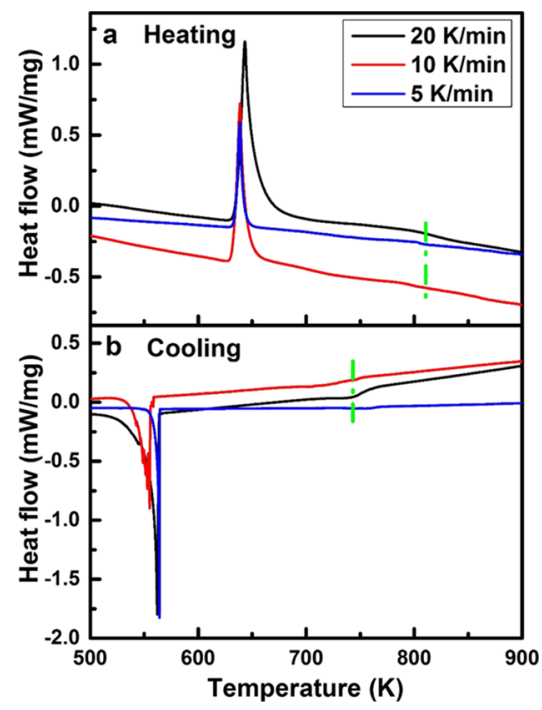

Figure 4. DSC measurements using different heating and cooling rates. Heat flow for $\mathrm{Au}_{55} \mathrm{Cu}_{25} \mathrm{Si}_{20}$ alloy from 500 to $900 \mathrm{~K}$ using heating rates from 5, 10, and $20 \mathrm{~K} / \mathrm{min}$ in a high-purity $\mathrm{Ar}$ atmosphere by PerkinElmer DSC-7, (a) during heating and (b) during cooling. The temperature for the broad dip marked by dash lines remains almost unchanged using various heating rates of 5,10 , and $20 \mathrm{~K} / \mathrm{min}$, indicating that the observed LLT in liquid $\mathrm{Au}_{55} \mathrm{Cu}_{25} \mathrm{Si}_{20}$ alloy does not depend on the heating rate. Temperatures for the machine PerkinElmer DSC-7 were calibrated using standard pure In and $\mathrm{Sn}$ for different heating rates used here.

heat capacity, measured during heating, initially decreases very slowly with temperature from 723 to $800 \mathrm{~K}$, but a distinct heat capacity peak emerges around $835 \mathrm{~K}$. It is striking that the observed broad dip in heat flow and heat capacity peak both lie in the same temperature ranges as the transitions observed in the temperature-dependent first peak position of $S(q)$ (Figure 2a) during heating. Small-angle X-ray scattering results for liquid $\mathrm{Au}_{55} \mathrm{Cu}_{25} \mathrm{Si}_{20}$ alloy performed in a temperature range from 673 to $1174 \mathrm{~K}$ during the entire heating and cooling cycle at a rate of $10 \mathrm{~K} / \mathrm{min}$ in Figure 5 reveal that the data of scattering intensity versus $q$ vector in the range of $q=0.2-5.2$

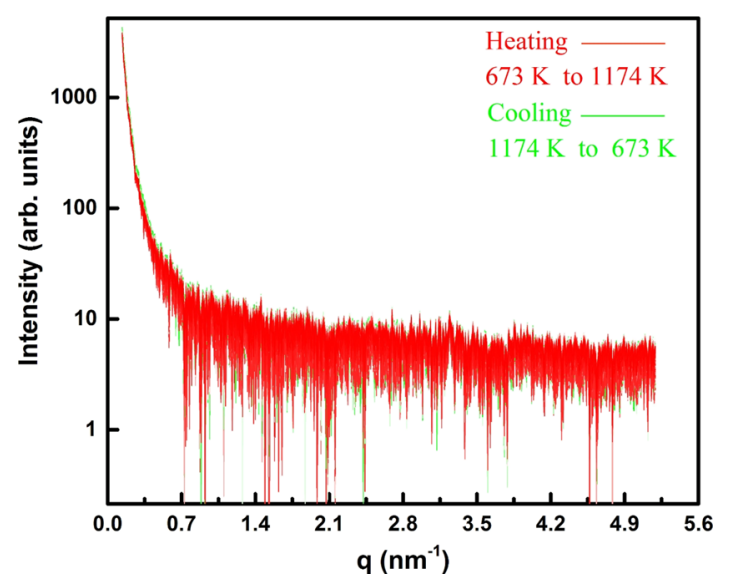

Figure 5. Small-angle X-ray scattering measurements. Small-angle Xray scattering measurements for liquid $\mathrm{Au}_{55} \mathrm{Cu}_{25} \mathrm{Si}_{20}$ alloy in a temperature range from 673 to $1174 \mathrm{~K}$ during the entire heating and cooling cycle using a rate of $10 \mathrm{~K} / \mathrm{min}$. No phase separation in the studied temperature range and $q$ range of $q=0.2-5.2 \mathrm{~nm}^{-1}$ was observed for liquid $\mathrm{Au}_{55} \mathrm{Cu}_{25} \mathrm{Si}_{20}$ alloy. During the entire heating and cooling cycle, the scattering intensity data as a function of $q$ overlapped each other.

$\mathrm{nm}^{-1}$ during heating are overlapped with those during cooling. No phase separation in the studied temperature range is observed in the liquid $\mathrm{Au}_{55} \mathrm{Cu}_{25} \mathrm{Si}_{20}$ alloy. All experimental results obtained above point out that the liquid $\mathrm{Au}_{55} \mathrm{Cu}_{25} \mathrm{Si}_{20}$ alloy exhibits a temperature-induced LLPT from a lowtemperature liquid phase below about $700 \mathrm{~K}$ to a hightemperature liquid phase above about $900 \mathrm{~K}$ at ambient pressure, which is reversible during heating and cooling.

For pure liquids, it is known that samples solidified from liquids at different temperatures could have different structures. Thus, we further studied the $\mathrm{Au}_{55} \mathrm{Cu}_{25} \mathrm{Si}_{20}$ alloys quenched from high-temperature (above $900 \mathrm{~K}$ ) and lowtemperature (below $750 \mathrm{~K}$ ) liquid phases by the melt-spinning method. Figure S3a shows their XRD patterns, demonstrating that the alloy quenched below $750 \mathrm{~K}$ contains some crystals, while the alloy quenched above $900 \mathrm{~K}$ is pure amorphous, confirming that our two samples at $300 \mathrm{~K}$ solidified from lowand high-temperature liquid phases indeed exhibit slight different structures. Moreover, DSC curves in Figure S3b exhibit slightly different glass transition and crystallization temperatures in both alloys and crystallization exothermal heat releases of $14.6 \mathrm{~J} / \mathrm{g}$ for the alloy quenched below $750 \mathrm{~K}$ and of $15.5 \mathrm{~J} / \mathrm{g}$ for the alloy quenched above $900 \mathrm{~K}$. Despite the existence of LLPT in liquid $\mathrm{Au}_{55} \mathrm{Cu}_{25} \mathrm{Si}_{20}$ alloy, previous studies revealed that the AuSi-based metallic liquids might have a surface crystalline layer. ${ }^{67-71}$ Hence, the influence of the surface crystalline layer to the LLPT should be considered. In AuSi-based metallic liquids, the surface crystalline layer has a thickness of about $6-7$ atomic layers, about $2 \mathrm{~nm} .{ }^{69-71}$ For the liquid sample studied here with a diameter of $0.7 \mathrm{~mm}$, if the surface crystalline layer would exist in our sample, the volume ratio of the surface crystalline layer to the total sample volume is roughly estimated to be about $6 \times 10^{-6}$. On the other hand, the thermal expansion coefficient of the bulk liquid $\mathrm{Au}_{55} \mathrm{Cu}_{25} \mathrm{Si}_{20}$ alloy is about $3.7 \times 10^{-5} \mathrm{~K}^{-1}$ below $770 \mathrm{~K}$ during heating and changes to about $7.5 \times 10^{-5} \mathrm{~K}^{-1}$ above $900 \mathrm{~K}$ 
during heating. The change of the thermal expansion coefficient of the bulk liquid $\mathrm{Au}_{55} \mathrm{Cu}_{25} \mathrm{Si}_{20}$ alloy during the transition is two times. Because the thermal expansion coefficient of bulk liquid $\mathrm{Au}_{55} \mathrm{Cu}_{25} \mathrm{Si}_{20}$ alloy is strongly linked with the average atomic bond strength in the whole sample; therefore, the change in the thermal expansion coefficient of the bulk liquid $\mathrm{Au}_{55} \mathrm{Cu}_{25} \mathrm{Si}_{20}$ alloy cannot be caused by minor 6 $\times 10^{-6}$ volume fraction of the surface crystalline layer.

Figure $6 \mathrm{a}, \mathrm{b}$ shows a series of integrated diffraction patterns of the $\mathrm{Au}_{55} \mathrm{Cu}_{25} \mathrm{Si}_{20} \mathrm{MG}$ during the compression up to 36.8

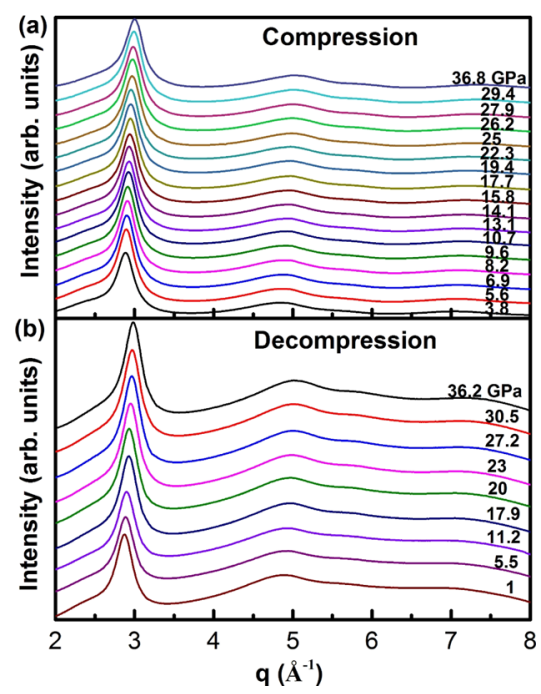

Figure 6. In situ high-energy high-pressure synchrotron XRD patterns. In situ high-pressure XRD patterns of $\mathrm{Au}_{55} \mathrm{Cu}_{25} \mathrm{Si}_{20} \mathrm{MG}$ in a DAC. (a) Integrated XRD patterns upon compression up to 36.8 GPa. (b) Integrated XRD patterns at selected pressures during decompression in the pressure range from 36.2 to $1 \mathrm{GPa}$.

GPa, followed by decompression at ambient temperature, respectively. During the entire compression and decompression range, the sample retains a fully amorphous structure, as examined from the smooth broad patterns in Figure 6, suggesting no pressure-induced crystallization reaction in the studied pressure range. The inverse first and second diffraction peak positions, $2 \pi / q_{1}$ and $2 \pi / q_{2}$, are shown in Figure $7 \mathrm{a}$, which

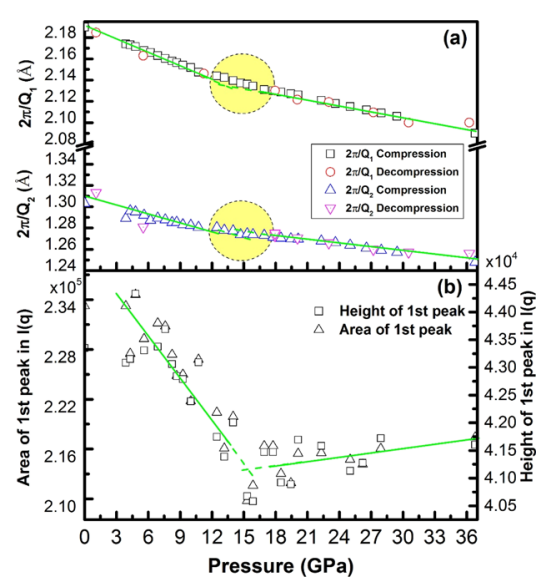

Figure 7. Structural changes. (a) Inverse peak positions $2 \pi / q_{1}$ and $2 \pi / q_{2}$ of $\mathrm{Au}_{55} \mathrm{Cu}_{25} \mathrm{Si}_{20} \mathrm{MG}$ upon compression and decompression as a function of pressure. (b) Pressure-induced changes of area (or intensity) and height of the first peak in $I(q)$. are deduced from the diffraction peak fitting. A fitting procedure is described in Supporting Information. The $2 \pi / q_{1}$ and $2 \pi / q_{2}$ exhibit a monotonic decrease with an obvious deviation from the linearity to the fitted curves around $13 \mathrm{GPa}$ during compression. The deviation proceeds further and then agrees linearly again with the fitted curves of $2 \pi / q_{1}$ and $2 \pi / q_{2}$ as the function of pressure above $15.8 \mathrm{GPa}$. During decompression, both $\left(2 \pi / q_{1}\right.$ and $\left.2 \pi / q_{2}\right)$ are reversible. Pressure-dependent peak height and their respective area (or intensity) of the first peak in $I(q)$ are plotted in Figure $7 \mathrm{~b}$. It is clear that peak height and intensity decrease with pressure in the range of $0-15 \mathrm{GPa}$, and then above about $15 \mathrm{GPa}$, both increase with pressure. The abnormal pressure-dependent $2 \pi$ / $q_{1}, 2 \pi / q_{2}$, and the first peak height and area all demonstrate an existence of possible two glassy phases separated by a pressure region of 13.1 to $15.8 \mathrm{GPa}$ during compression, revealing a pressure-induced reversible AAPT in the $\mathrm{Au}_{55} \mathrm{Cu}_{25} \mathrm{Si}_{20} \mathrm{MG}$.

Next, we address structural differences between lowtemperature and high-temperature phases in the liquid $\mathrm{Au}_{55} \mathrm{Cu}_{25} \mathrm{Si}_{20}$ alloy at ambient pressure and low-pressure and high-pressure amorphous phases in the $\mathrm{Au}_{55} \mathrm{Cu}_{25} \mathrm{Si}_{20} \mathrm{MG}$ at ambient temperature by AIMD simulations. Figure 8
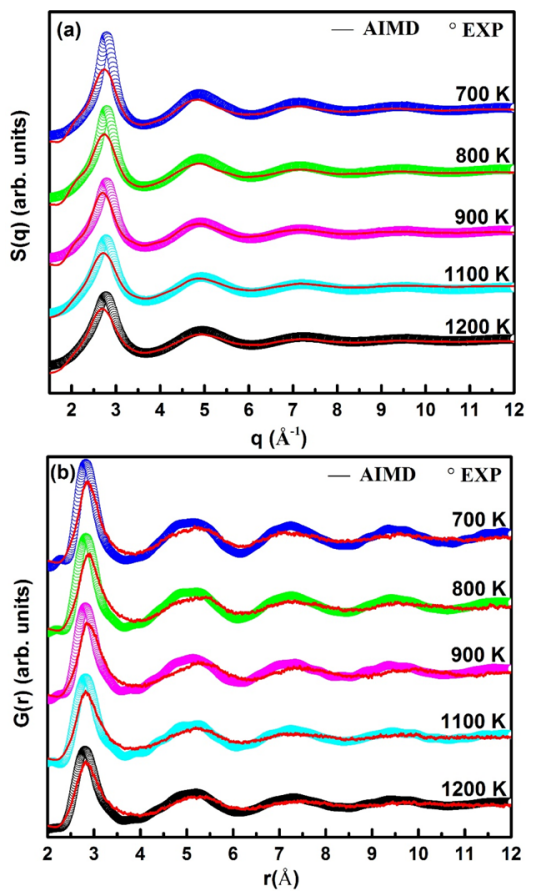

Figure 8. $S(q)$ and $G(r)$ for liquid $\mathrm{Au}_{55} \mathrm{Cu}_{25} \mathrm{Si}_{20}$ alloy. (a) Structure factors $S(q)$ and $(b)$ reduced pair distribution functions $G(r)$ for liquid $\mathrm{Au}_{55} \mathrm{Cu}_{25} \mathrm{Si}_{20}$ alloy at five selected temperatures acquired from synchrotron radiation XRD measurements (open circles) and AIMD simulations (solid lines).

demonstrates structure factors $S(q)$ and reduced pair distribution functions $G(r)$ of liquid $\mathrm{Au}_{55} \mathrm{Cu}_{25} \mathrm{Si}_{20}$ alloy at five selected temperatures acquired from synchrotron radiation XRD measurements and AIMD simulations. The consistency, in terms of peak positions, amplitudes, and shapes, between the data extracted from AIMD simulations and XRD measurements is ascertained, indicating that AIMD simulations capture the major feature of atomic configurations in the liquid $\mathrm{Au}_{55} \mathrm{Cu}_{25} \mathrm{Si}_{20}$ alloy. From $\mathrm{Au}$-, $\mathrm{Cu}$-, and $\mathrm{Si}$-centered partial pair correlation functions (PPCFs), $g(r)$, at various temperatures in 
Supporting Information Figure S5, it is found that the peak positions and the coordination numbers $(\mathrm{CNs})$ of the first shell in $\mathrm{Au}$ - and $\mathrm{Cu}$-centered PPCFs in Figure 9a decrease with

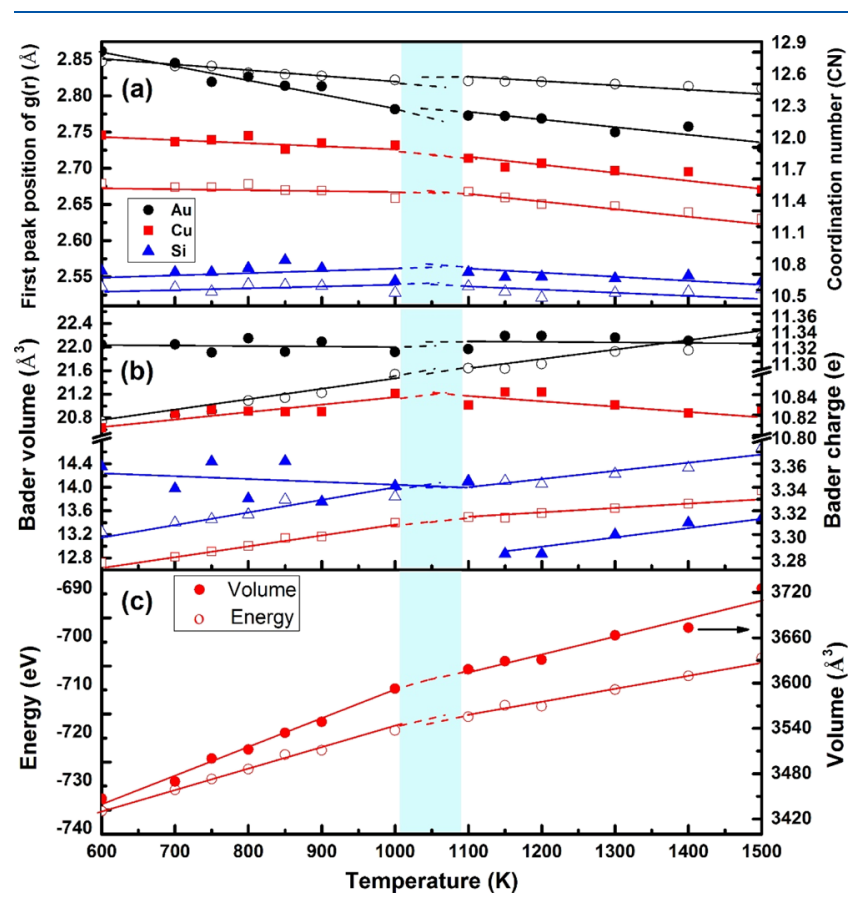

Figure 9. Temperature-induced structural evolution via AIMD simulations. Temperature dependent structural evolution for liquid $\mathrm{Au}_{55} \mathrm{Cu}_{25} \mathrm{Si}_{20}$ alloy obtained from AIMD simulations. Filled symbols and open symbols are for right and left $y$ axes, respectively, while solid lines are a guide to the eye only. (a) Peak positions and CNs of the first peak in $\mathrm{Au}$ - (circles), $\mathrm{Cu}$ - (squares), and Si-centered (triangles) $g(r)$ in liquid $\mathrm{Au}_{55} \mathrm{Cu}_{25} \mathrm{Si}_{20}$ alloy obtained from AIMD simulations. (b) Bader volumes and Bader charges of $\mathrm{Au}$ (circles), $\mathrm{Cu}$ (squares), and $\mathrm{Si}$ (triangles) atoms in liquid $\mathrm{Au}_{55} \mathrm{Cu}_{25} \mathrm{Si}_{20}$ alloy obtained from AIMD simulations. (c) Total energy (open circles) and volume (filled circles) of the liquid $\mathrm{Au}_{55} \mathrm{Cu}_{25} \mathrm{Si}_{20}$ system used in AIMD simulations. rising temperature. Kinks are observed at around 1000-1100 $\mathrm{K}$, which reveal that temperature dependences of the peak positions and the $\mathrm{CNs}$ of the first shell in $\mathrm{Au}$ - and $\mathrm{Cu}$-centered PPCFs at the low-temperature phase differ from those at the high-temperature phase of liquid $\mathrm{Au}_{55} \mathrm{Cu}_{25} \mathrm{Si}_{20}$ alloy. For the Sicentered first shell, both the temperature-dependent parameters at the low-temperature phase deviate at around 1000$1100 \mathrm{~K}$ from those at the high-temperature phase, which is supported by the Bader charge and volume analyses ${ }^{72}$ as shown in Figure 9b, in which atomic volume is uniquely defined by the charge density topology as the region bound by zero flux surfaces and the charge within the Bader volume. During cooling, Bader charge of $\mathrm{Si}$ atoms in the liquid $\mathrm{Au}_{55} \mathrm{Cu}_{25} \mathrm{Si}_{20}$ alloy suddenly increases at $1100 \mathrm{~K}$ by a value of $0.6 e$ per atom, while they slightly decrease for $\mathrm{Au}$ and $\mathrm{Cu}$ atoms. Besides, kinks are also detected for the temperaturedependent Bader volumes of $\mathrm{Au}, \mathrm{Cu}$, and $\mathrm{Si}$ atoms at around $1000-1100 \mathrm{~K}$ as shown in Figure $9 \mathrm{~b}$ and the temperaturedependent total energy and volume of the system as shown in Figure 9c.

Figure S6 in Supporting Information shows total pair correlation function and PPCF $g(r)$ at selected pressures obtained by AIMD simulations at ambient temperature. $g_{\mathrm{Au}-\mathrm{Au}}(r)$ is the major among all partial PCFs, followed by $g_{\mathrm{Au}-\mathrm{Cu}}(r)$ and then $g_{\mathrm{Au}-\mathrm{Si}}(r)$, contributing to total PCF, while other bonds, for example, $\mathrm{Cu}-\mathrm{Cu}, \mathrm{Cu}-\mathrm{Si}$, and $\mathrm{Si}-\mathrm{Si}$ bonds, are almost negligible. It is found that $\mathrm{Au}-\mathrm{Cu}$ and $\mathrm{Au}-\mathrm{Si}$ bonds are to a greater extent densely packed as compared to $\mathrm{Au}-\mathrm{Au}$ bonds. The Pressure-dependent first peak position of $g(r)$ and volume of the system are plotted in Figure 10a, while pressuredependent energy and density of the system are shown in Figure 10b. All data reveal different pressure dependences of all four parameters below and above around 13 to $15.4 \mathrm{GPa}$. Two different glassy phases revealed in experiments in Figures 6 and 7 are supported by these AIMD results, that is, in the lowpressure region below $\sim 13 \mathrm{GPa}$, the system energy increased relatively slow and the system density increased relatively fast with pressure as compared to these in the high-pressure region above 15.4 GPa. By using Voronoi tessellation analysis, ${ }^{73}$ the
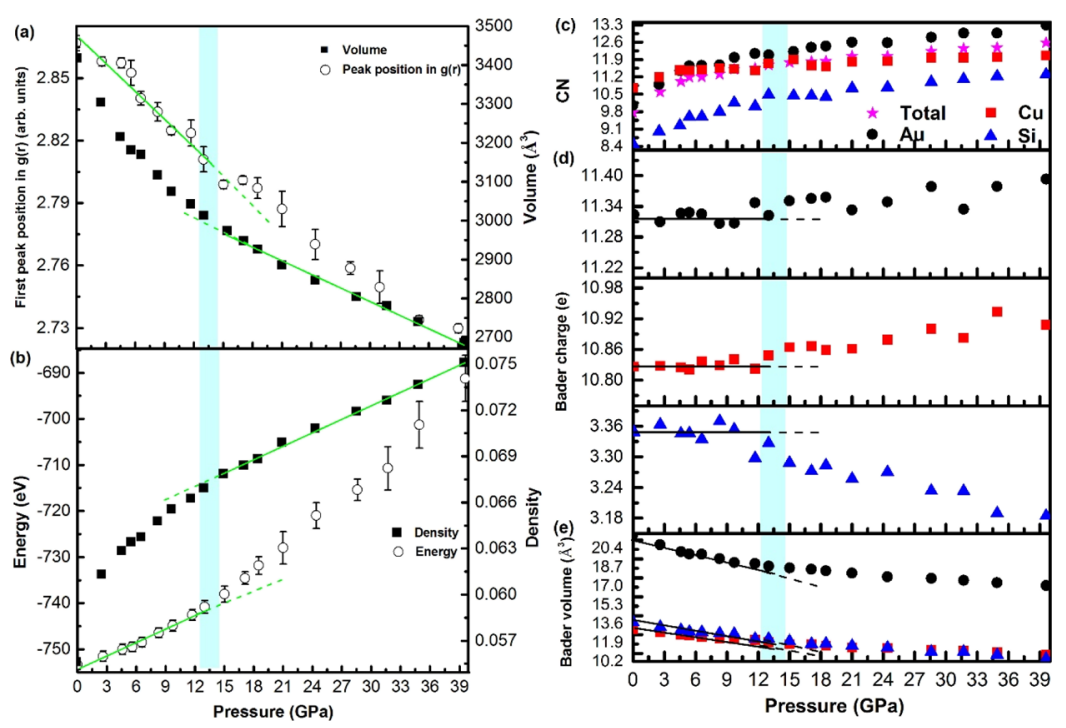

Figure 10. Pressure-induced structural evolution via $\mathrm{AIMD}$ simulations. (a) First peak position in $g(r)$ and volume of $\mathrm{Au}_{55} \mathrm{Cu}_{25} \mathrm{Si}_{20} \mathrm{MG}$ as a function of pressure. (b) Pressure-dependent energy and density of $\mathrm{Au}_{55} \mathrm{Cu}_{25} \mathrm{Si}_{20} \mathrm{MG}$. The pressure dependences of CNs (c), Bader charge (d), and Bader volume (e) of $\mathrm{Au}, \mathrm{Cu}$, and $\mathrm{Si}$ atoms in $\mathrm{Au}_{55} \mathrm{Cu}_{25} \mathrm{Si}_{20} \mathrm{MG}$. 
evolution of atomic packing is analyzed. The details of this technique can be found in Supporting Information. The top eleven major VP fractions for $\mathrm{Au}-, \mathrm{Cu}-$, and $\mathrm{Si}$-centered atoms under various pressures are plotted in Figure S7. The most abundant VPs centered by $\mathrm{Au}$ atoms are $\mathrm{CN}=11,\langle 0,2,8,1\rangle$, $\mathrm{CN}=12,\langle 0,3,6,3\rangle$ and $\langle 0,2,8,2\rangle$ in the low-pressure phase, and they are shifted to VPs $\mathrm{CN}=13,\langle 0,3,6,4\rangle$ and $\langle 0,1,102\rangle$ in the high-pressure phase. Silicon atoms favor low-coordinated polyhedra at the low-pressure phase, that is, $\mathrm{CN}=8\langle 0,4,4,0\rangle$, $\mathrm{CN}=9\langle 0,3,6,0\rangle$ and $\mathrm{CN}=10\langle 0,3,6,1\rangle,\langle 0,2,8,0\rangle$, while above the transition pressure, their fractions are significantly reduced and they shift to higher $\mathrm{CN}=11\langle 0,2,8,1\rangle$ and $\mathrm{CN}=12$ $\langle 0,3,6,3\rangle$ VPs. The average total and partial $\mathrm{CNs}$ of $\mathrm{Au}-, \mathrm{Cu}-$, and $\mathrm{Si}$-centered atoms at various pressures in $\mathrm{Au}_{55} \mathrm{Cu}_{25} \mathrm{Si}_{20} \mathrm{MG}$ are plotted in Figure 10c. At zero pressure, they are found to be $\mathrm{CN}_{\text {total }}=9.7 \pm 0.1, \mathrm{CN}_{\mathrm{Au}}=10.1 \pm 0.1, \mathrm{CN}_{\mathrm{Cu}}=10.8 \pm 0.1$, and $\mathrm{CN}_{\mathrm{Si}}=8.5 \pm 0.2$, while at $39.6 \mathrm{GPa}, \mathrm{CN}_{\text {total }}=12.5 \pm 0.1$, $\mathrm{CN}_{\mathrm{Au}}=13.2 \pm 0.1, \mathrm{CN}_{\mathrm{Cu}}=12.1 \pm 0.1$, and $\mathrm{CN}_{\mathrm{Si}}=11.3 \pm 0.2$. At low-pressure below about $10 \mathrm{GPa}$, the $\mathrm{CN}_{\text {total }}, \mathrm{CN}_{\mathrm{Au}}, \mathrm{CN}_{\mathrm{Cu}}$, and $\mathrm{CN}_{\mathrm{Si}}$ increase with pressure, while at higher pressure above about 10-15 GPa, their rates of increment become much slow. The Bader charge and volume analyses of $\mathrm{Au}, \mathrm{Cu}$, and $\mathrm{Si}$ elements in $\mathrm{Au}_{55} \mathrm{Cu}_{25} \mathrm{Si}_{20}$ MG (Figure 10d,e) reveal that in the low-pressure range below about $12 \mathrm{GPa}$, no obvious changes are observed in the charge transfer among elements as shown by the guided line within uncertainty. Bader charge of $\mathrm{Si}$ atoms in $\mathrm{Au}_{55} \mathrm{Cu}_{25} \mathrm{Si}_{20} \mathrm{MG}$ starts to decrease at around $13 \mathrm{GPa}$, while they slightly increase for $\mathrm{Au}$ and $\mathrm{Cu}$ atoms. Kinks are detected for pressure-dependent Bader volumes at around 11.7 to 15 $\mathrm{GPa}$ with different slopes of $\mathrm{Au}, \mathrm{Cu}$, and $\mathrm{Si}$ atoms. The size of $\mathrm{Si}$ atoms is larger than that of $\mathrm{Cu}$ atoms at zero pressure, and it decreases relatively fast with pressure and becomes smaller than $\mathrm{Cu}$ atoms at $39.6 \mathrm{GPa}$, which is due to the charge transfer from $\mathrm{Si}$ to $\mathrm{Cu}$ and $\mathrm{Au}$ atoms. The sharp shift of low coordinated polyhedra to high coordinated polyhedral, the total and partial $\mathrm{CN}$ changes around $\mathrm{Au}$ - and Si-centered atoms, and the unusual behavior of charge transfer, the phenomena which were observed from AIMD simulations, support the experimental observation in Figures 6 and 7, that is, the existence of pressure-induced AAPT in the $\mathrm{Au}_{55} \mathrm{Cu}_{25} \mathrm{Si}_{20}$ $\mathrm{MG}$ at around $10-15 \mathrm{GPa}$ and ambient temperature, from both atomic packing structure and electronic structure points of view.

\section{CONCLUSIONS}

In summary, polyamorphic transitions of LLPT and AAPT in the $\mathrm{Au}_{55} \mathrm{Cu}_{25} \mathrm{Si}_{20}$ alloy system have been investigated by both experimental XRD and DSC measurements and ab initio molecular dynamics (AIMD) simulations. We found solid experimental evidence for the existence of both temperatureinduced LLPT in the liquid $\mathrm{Au}_{55} \mathrm{Cu}_{25} \mathrm{Si}_{20}$ alloy in a temperature range of $700-900 \mathrm{~K}$ at ambient pressure and pressure-induced AAPT in the $\mathrm{Au}_{55} \mathrm{Cu}_{25} \mathrm{Si}_{20} \mathrm{MG}$ from $\sim 13.1$ to $\sim 15.8 \mathrm{GPa}$ at ambient temperature. The temperatureinduced LLPT is characterized by "reversible $\lambda$-anomalies" of the volume thermal expansion coefficient, heat flow, and heat capacity peaks at the transition, together with different temperature-dependent first peak positions of $\mathrm{Au}-, \mathrm{Cu}-$, and Si-centered PPCF, CN of the $\mathrm{Au}-, \mathrm{Cu}$-, and $\mathrm{Si}$-centered first shell, Bader volume and charge of $\mathrm{Au}, \mathrm{Cu}$, and $\mathrm{Si}$ atoms, and total energy and volume of the system below and above the transition. The pressure-induced AAPT is characterized by different pressure dependences of peak position, volume, energy, density, $\mathrm{CN}$, and Bader volumes and charges of the $\mathrm{Au}-, \mathrm{Cu}$-, and $\mathrm{Si}$-centered atoms in the system below and above the AAPT. These changes in the system suggest that the temperature and pressure lead to the collapse of initial atomic configuration of the local structure in the $\mathrm{Au}_{55} \mathrm{Cu}_{25} \mathrm{Si}_{20}$ alloy, and their effects are not restricted only by the changes in the atomic arrangement but also in the electronic structure. Most likely, the temperature- and pressure-induced electronic transfer from $\mathrm{Si}$ atoms to $\mathrm{Au}$ and/or $\mathrm{Cu}$ atoms play an important role for both temperature-induced LLPT and pressure-induced AAPT in the $\mathrm{Au}_{55} \mathrm{Cu}_{25} \mathrm{Si}_{20}$ alloy. This unique finding, that is, the existence of both temperature-induced LLPT and pressure-induced AAPT in the $\mathrm{Au}_{55} \mathrm{Cu}_{25} \mathrm{Si}_{20}$ alloy, will trigger more challenging studies in disordered systems, especially metallic systems. For example, (1) what kind of systems could have both LLPT and AAPT? (2) What are the exact atomic structures from a microscopic point of view in both low-temperature or low-pressure, and high-temperature or high-pressure phases in the $\mathrm{Au}_{55} \mathrm{Cu}_{25} \mathrm{Si}_{20}$ alloy? (3) Is there any kind of hidden correlation of the LLPT with the AAPT in the $\mathrm{Au}_{55} \mathrm{Cu}_{25} \mathrm{Si}_{20}$ alloy? (4) What are the order parameters for the LLPT and AAPT in disordered materials in general? (5) Are they only the strong-to-fragile transition or similar to the polymorphism in crystalline materials?

\section{ASSOCIATED CONTENT}

\section{S Supporting Information}

The Supporting Information is available free of charge on the ACS Publications website at DOI: 10.1021/acs.jpcc.9b05167.

Temperature-dependent parameter of $\left(q_{1}\left(T_{\mathrm{o}}\right) / q_{1}(T)\right)^{n}$ and the slopes of $\left(q_{1}\left(T_{\mathrm{o}}\right) / q_{1}(T)\right)^{n}$ vs $T$ for liquid $\mathrm{Au}_{55} \mathrm{Cu}_{25} \mathrm{Si}_{20}$ alloy; fwhm of the first peak of $S(q)$ versus temperature during thermal cycles; XRD and DSC scattering measurements for $\mathrm{Au}_{55} \mathrm{Cu}_{25} \mathrm{Si}_{20}$ alloys quenched from two different liquid states; fitting of the first peak of scattering intensity; $\mathrm{Au}-, \mathrm{Cu}-$, and $\mathrm{Si}$ centered, $\mathrm{Au}-\mathrm{Au}, \mathrm{Cu}-\mathrm{Cu}$, and $\mathrm{Si}-\mathrm{Si}$ PPCFs, $g(r)$, obtained from AIMD simulations at selected temperatures for liquid $\mathrm{Au}_{55} \mathrm{Cu}_{25} \mathrm{Si}_{20}$ alloy; the total and PPCFs, $g(r)$ of $\mathrm{Au}_{55} \mathrm{Cu}_{25} \mathrm{Si}_{20} \mathrm{MG}$ at various pressure obtained via AIMD simulation; Voronoi tessellation analysis to analyze the evolution of atomic packing; structural features obtained from Voronoi tessellation; and the distribution of the most abundant Voronoi polyhedra (a) total (b) Au-, (c) Cu- and (d) Si-centered atoms in $\mathrm{Au}_{55} \mathrm{Cu}_{25} \mathrm{Si}_{20} \mathrm{MG}$ during compression (PDF)

\section{AUTHOR INFORMATION}

\section{Corresponding Authors}

*E-mail: wangxd@zju.edu.cn (X.-D.W.).

*E-mail: jiangjz@zju.edu.cn (J.-Z.J.).

ORCID

Hao Wang: 0000-0001-8896-5496

Jian-Zhong Jiang: 0000-0001-9504-1726

\section{Author Contributions}

J.-Z.J. designed and supervised this study, S.A.K. prepared the samples and AIMD simulations, A.S.A., X.-D.W., Q.-P.C., D.X.Z., Y.-Z.F., and J.-Z.J. conducted measurements, S.A.K., X.D.W., Q.-P.C., D.-X.Z., Y.-Z.F., H.W., and J.-Z.J. contributed to data analyses and discussion, and J.-Z.J. wrote the manuscript. 


\section{Notes}

The authors declare no competing financial interest.

\section{ACKNOWLEDGMENTS}

The beamtime support at 11-ID-C and Sector one at Advance Photon Source, Argonne National Laboratory and at P02.2, PetraIII is greatly appreciated. Financial supports from the National Natural Science Foundation of China (U1832203, 51671170, U1532115, and 51671169), National Key Research and Development Program of China (2016YFB0701203, 2017 YFA0403400 and 2016YFB0700201), NSF of Zhejiang Province (Z1110196, Y4110192 and LY15E010003), and the Fundamental Research Funds for the Central Universities are gratefully acknowledged. The computer resources at National Supercomputer Centers in Tianjin and Special Program for Applied Research on Super Computation of the NSFCGuangdong Joint Fund (the second phase) under grant no. U1501501 are also gratefully acknowledged.

\section{REFERENCES}

(1) Mishima, O.; Calvert, L. D.; Whalley, E. 'Melting ice' I at $77 \mathrm{~K}$ and 10 kbar: a new method of making amorphous solids. Nature 1984, 310, 393-395.

(2) Bhat, M. H.; Molinero, V.; Soignard, E.; Solomon, V. C.; Sastry, S.; Yarger, J. L.; Angell, C. A. Vitrification of a monatomic metallic liquid. Nature 2007, 448, 787-790.

(3) Sastry, S. The relationship between fragility, configurational entropy and the potential energy landscape of glass-forming liquids. Nature 2001, 409, 164-167.

(4) Xu, L.; Buldyrev, S. V.; Angell, C. A.; Stanley, H. E. Thermodynamics and dynamics of the two-scale spherically symmetric jagla ramp model of anomalous liquids. Phys. Rev. E: Stat., Nonlinear, Soft Matter Phys. 2006, 74, 031108.

(5) Deb, S. K.; Wilding, M.; Somayazulu, M.; McMillan, P. F. Pressure-induced amorphization and an amorphous-amorphous transition in densified porous silicon. Nature 2001, 414, 528-530.

(6) Perottoni, C. A.; da Jornada, J. A. H. Pressure-induced amorphization and negative thermal expansion in $\mathrm{ZrW}_{2} \mathrm{O}_{8}$. Science 1998, 280, 886-889.

(7) Molinero, V.; Sastry, S.; Angell, C. A. Tuning of tetrahedrality in a silicon potential yields a series of monatomic (Metal-like) glass formers of very high fragility. Phys. Rev. Lett. 2006, 97, 075701.

(8) McMillan, P. F. Polyamorphic transformations in liquids and glasses. J. Mater. Chem. 2004, 14, 1506-1512.

(9) Sastry, S.; Austen Angell, C. Liquid-liquid phase transition in supercooled silicon. Nat. Mater. 2003, 2, 739-743.

(10) Beye, M.; Sorgenfrei, F.; Schlotter, W. F.; Wurth, W.; Fohlisch, A. The liquid-liquid phase transition in silicon revealed by snapshots of valence electrons. Proc. Natl. Acad. Sci. U.S.A. 2010, 107, 1677216776.

(11) Ganesh, P.; Widom, M. Liquid-liquid transition in supercooled silicon determined by first-principles simulation. Phys. Rev. Lett. 2009, 102, 075701.

(12) Katayama, Y.; Mizutani, T.; Utsumi, W.; Shimomura, O.; Yamakata, M.; Funakoshi, K.-i. A first-order liquid-liquid phase transition in phosphorus. Nature 2000, 403, 170-173.

(13) Katayama, Y.; Inamura, Y.; Mizutani, T.; Yamakata, M.; Utsumi, W.; Shimomura, O. Macroscopic separation of dense fluid phase and liquid phase of phosphorus. Science 2004, 306, 848-851.

(14) Glosli, J. N.; Ree, F. H. Liquid-liquid phase transformation in carbon. Phys. Rev. Lett. 1999, 82, 4659.

(15) Saika-Voivod, I.; Poole, P. H.; Sciortino, F. Fragile-to-strong transition and polyamorphism in the energy landscape of liquid silica. Nature 2001, 412, 514-517.

(16) Poole, P. H.; Hemmati, M.; Angell, C. A. Comparison of thermodynamic properties of simulated liquid silica and water. Phys. Rev. Lett. 1997, 79, 2281.
(17) Aasland, S.; Mcmillan, P. F. Density-driven liquid-liquid phase separation in the system $\mathrm{AI}_{2} \mathrm{O}_{3}-\mathrm{Y}_{2} \mathrm{O}_{3}$. Nature 1994, 369, 633-636.

(18) Greaves, G. N.; Wilding, M. C.; Fearn, S.; Langstaff, D.; Kargl, F.; Cox, S.; Van, Q. V.; Majerus, O.; Benmore, C. J.; Weber, R.; et al. Detection of first-order liquid/liquid phase transitions in yttrium oxide-aluminum oxide melts. Science 2008, 322, 566-570.

(19) Ito, K.; Moynihan, C. T.; Angell, C. A. Thermodynamic determination of fragility in liquids and a fragile-to-strong liquid transition in water. Nature 1999, 398, 492-495.

(20) Mishima, O.; Stanley, H. E. The relationship between liquid, supercooled and glassy water. Nature 1998, 396, 329-335.

(21) Poole, P. H.; Sciortino, F.; Essmann, U.; Stanley, H. E. Phase behaviour of metastable water. Nature 1992, 360, 324-328.

(22) Kurita, R.; Tanaka, H. Critical-like phenomena associated with liquid-liquid transition in a molecular liquid. Science 2004, 306, 845848.

(23) Mishima, O.; Calvert, L. D.; Whalley, E. An apparently firstorder transition between two amorphous phases of ice induced by pressure. Nature 1985, 314, 76-78.

(24) Meade, C.; Hemley, R. J.; Mao, H. K. High-pressure x-ray diffraction of SiO2 glass. Phys. Rev. Lett. 1992, 69, 1387.

(25) Morishita, T. High density amorphous form and polyamorphic transformations of silicon. Phys. Rev. Lett. 2004, 93, 055503.

(26) McMillan, P. F.; Wilson, M.; Daisenberger, D.; Machon, D. A density-driven phase transition between semiconducting and metallic polyamorphs of silicon. Nat. Mater. 2005, 4, 680-684.

(27) Lee, S. K.; Eng, P. J.; Mao, H.-k.; Meng, Y.; Newville, M.; Hu, M. Y.; Shu, J. Probing of bonding changes in $\mathrm{B}_{2} \mathrm{O}_{3}$ glasses at high pressure with inelastic x-ray scattering. Nat. Mater. 2005, 4, 851-854.

(28) Raty, J.-Y.; Schwegler, E.; Bonev, S. A. Electronic and structural transitions in dense liquid sodium. Nature 2007, 449, 448-451.

(29) Tamblyn, I.; Raty, J.-Y.; Bonev, S. A. Tetrahedral clustering in molten lithium under pressure. Phys. Rev. Lett. 2008, 101, 075703.

(30) Lou, H.; Wang, X.; Cao, Q.; Zhang, D.; Zhang, J.; Hu, T.; Mao, H.-K.; Jiang, J.-Z. Negative expansions of interatomic distances in metallic melts. Proc. Natl. Acad. Sci. U.S.A. 2013, 110, 10068-10072.

(31) Xu, W.; Sandor, M. T.; Yu, Y.; Ke, H. B.; Zhang, H. P.; Li, M. Z.; Wang, W. H.; Liu, L. Evidence of liquid-liquid transition in glassforming $\mathrm{La}_{50} \mathrm{Al}_{35} \mathrm{Ni}_{15}$ melt above liquidus temperature. Nat. Commun. 2015, 6, 7696.

(32) Bryk, T.; Panfilis, S. De.; Gorelli, F. A.; Gregoryanz, E.; Krisch, M.; Ruocco, G.; Santoro, M.; Scopigno, T.; Seitsonen, A. P. Dynamical crossover at the liquid-liquid transformation of a compressed molten alkali metal. Phys. Rev. Lett. 2013, 111, 077801.

(33) Cadien, A.; Hu, Q. Y.; Meng, Y.; Cheng, Y. Q.; Chen, M. W.; Shu, J. F.; Mao, H. K.; Sheng, H. W. First-order liquid-liquid phase transition in cerium. Phys. Rev. Lett. 2013, 110, 125503.

(34) Xiong, L. H.; Wang, X. D.; Yu, Q.; Zhang, H.; Zhang, F.; Sun, Y.; Cao, Q. P.; Xie, H. L.; Xiao, T. Q.; Zhang, D. X.; et al. Temperature-dependent structure evolution in liquid gallium. Acta Mater. 2017, 128, 304-312.

(35) Wei, S.; Yang, F.; Bednarcik, J.; Kaban, I.; Shuleshova, O.; Meyer, A.; Busch, R. Liquid-liquid transition in a strong bulk metallic glass-forming liquid. Nat. Commun. 2013, 4, 2083.

(36) Kurita, R.; Tanaka, H. Control of the fragility of a glass-forming liquid using the liquid-liquid phase transition. Phys. Rev. Lett. 2005, 95, 065701

(37) Faraone, A.; Liu, L.; Mou, C.-Y.; Yen, C.-W.; Chen, S.-H. Fragile-to-strong liquid transition in deeply supercooled confined water. J. Chem. Phys. 2004, 121, 10843.

(38) Hechler, S.; Ruta, B.; Stolpe, M.; Pineda, E.; Evenson, Z.; Gross, O.; Bernasconi, A.; Busch, R.; Gallino, I. Microscopic evidence of the connection between liquid-liquid transition and dynamical crossover in an ultraviscous metallic glass former. Phys. Rev. Mater. 2018, 2, 085603.

(39) Zeng, Q. S.; Li, Y. C.; Feng, C. M.; Liermann, P.; Somayazulu, M.; Shen, G. Y.; Mao, H.-K.; Yang, R.; Liu, J.; Hu, T. D.; et al. Anomalous compression behavior in lanthanum/cerium-based 
metallic glass under high pressure. Proc. Natl. Acad. Sci. U.S.A. 2007, 104, 13565-13568.

(40) Sheng, H. W.; Liu, H. Z.; Cheng, Y. Q.; Wen, J.; Lee, P. L.; Luo, W. K.; Shastri, S. D.; Ma, E. Polyamorphism in a metallic glass. Nat. Mater. 2007, 6, 192-197.

(41) Zeng, Q.-s.; Ding, Y.; Mao, W. L.; Yang, W. G.; Sinogeikin, S. V.; Shu, J.; Mao, H.-k.; Jiang, J. Z. Origin of pressure-induced polyamorphism in $\mathrm{Ce}_{75} \mathrm{Al}_{25}$ metallic glass. Phys. Rev. Lett. 2010, 104, 105702.

(42) Zeng, Q. S.; Struzhkin, V. V.; Fang, Y. Z.; Gao, C. X.; Lou, H. B.; Wang, X. D.; Lathe, C.; Mao, F. M.; Wu, W. L.; Mao, H.-K.; et al. Properties of polyamorphous Ce75Al25 metallic glasses. Phys. Rev. B: Condens. Matter Mater. Phys. 2010, 82, 054111.

(43) Zeng, Q. S.; Fang, Y. Z.; Lou, H. B.; Gong, Y.; Wang, X. D.; Yang, K.; Li, A. G.; Yan, S.; Lathe, C.; Wu, F. M.; et al. Phase transformation from low-density to high-density $\mathrm{Ce}_{75} \mathrm{Al}_{23} \mathrm{Si}_{2}$ metallic glass. J. Phys.: Condens. Matter 2010, 22, 375404.

(44) Zeng, Q.; Sheng, H.; Ding, Y.; Wang, L.; Yang, W.; Jiang, J.-Z.; Mao, W. L.; Mao, H.-K. Long-range topological order in metallic glass. Science 2011, 332, 1404-1406.

(45) Li, G.; Wang, Y. Y.; Liaw, P. K.; Li, Y. C.; Liu, R. P. Electronic structure inheritance and pressure-induced polyamorphism in lanthanide-based metallic glasses. Phys. Rev. Lett. 2012, 109, 125501.

(46) Lin, C. L.; Ahmad, A. S.; Lou, H. B.; Wang, X. D.; Cao, Q. P.; Li, Y. C.; Liu, J.; Hu, T. D.; Zhang, D. X.; Jiang, J. Z. Pressure-induced amorphous-to-amorphous reversible transformation in $\operatorname{Pr}_{75} \mathrm{Al}_{25}$. J. Appl. Phys. 2013, 114, 213516.

(47) Wu, M.; Tse, J. S.; Wang, S. Y.; Wang, C. Z.; Jiang, J. Z. Origin of pressure induced crystallization of $\mathrm{Ce}_{75} \mathrm{Al}_{25}$ metallic glass. Nat. Commun. 2015, 6, 6493.

(48) Li, L.; Luo, Q.; Li, R.; Zhao, H.; Chapman, K. W.; Hupas, P. J.; Wang, L.; Liu, H. Polyamorphism in Yb-based metallic glass induced by pressure. Sci. Rep. 2017, 7, 46762.

(49) Lou, H. B.; Fang, Y. K.; Zeng, Q. S.; Lu, Y. H.; Wang, X. D.; Cao, Q. P.; Yang, K. X.; Yu, H.; Zheng, L.; Zhao, Y. D.; et al. Pressureinduced amorphous-to-amorphous configuration change in $\mathrm{Ca}-\mathrm{Al}$ metallic glasses. Sci. Rep. 2012, 2, 376.

(50) Wu, M.; Lou, H. B.; Tse, J. S.; Liu, H.; Pan, Y.; Takahama, K.; Matsuoka, T.; Shimizu, K.; Jiang, J. Z. Pressure-induced polyamorphism in a main-group metallic glass. Phys. Rev. B: Condens. Matter Mater. Phys. 2016, 94, 054201.

(51) Sheng, H. W.; Ma, E.; Liu, H. Z.; Wen, J. Pressure tunes atomic packing in metallic glass. Appl. Phys. Lett. 2006, 88, 171906.

(52) Mattern, N.; Bednarcik, J.; Liermann, H.-P.; Eckert, J. Structural behaviour of Pd40Cu30Ni10P20 metallic glass under high pressure. Intermetallics 2013, 38, 9-13.

(53) Lou, H. B.; Xiong, L. H.; Ahmad, A. S.; Li, A. G.; Yang, K.; Glazyrin, K.; Liermann, H. P.; Franz, H.; Wang, X. D.; Cao, Q. P.; et al. Atomic structure of $\mathrm{Pd}_{81} \mathrm{Si}_{19}$ glassy alloy under high pressure. Acta Mater. 2014, 81, 420-427.

(54) Hammersley, A. P.; Svensson, S. O.; Hanfland, M.; Fitch, A. N.; Hausermann, D. Two-dimensional detector software: From real detector to idealised image or two-theta scan. High Pressure Res. 1996, 14, 235.

(55) Jeong, I.-K.; Thompson, J.; Proffen, T.; Turner, A. M. P. PDFgetX: a program for obtaining the atomic pair distribution function from X-ray powder diffraction data. J. Appl. Crystallogr. 2001, 34, 536.

(56) Jiang, Q. K.; Wang, X. D.; Nie, X. P.; Zhang, G. Q.; Ma, H.; Fecht, H.-J.; Bendnarcik, J.; Franz, H.; Liu, Y. G.; Cao, Q. P.; et al. $\mathrm{Zr}-(\mathrm{Cu}, \mathrm{Ag})-\mathrm{Al}$ bulk metallic glasses. Acta Mater. 2008, 56, 17851796.

(57) Khan, S. A.; Wang, X. D.; Cao, Q. P.; Zhang, D. X.; Jiang, J. Z. Structural signature in Au-based amorphous alloys. Acta Mater. 2017, $140,31-38$.

(58) Kresse, G.; Furthmüller, J. Efficiency of ab-initio total energy calculations for metals and semiconductors using a plane-wave basis set. Comput. Mater. Sci. 1996, 6, 15-50.
(59) Hoover, W. G. Canonical dynamics: Equilibrium phase-space distributions. Phys. Rev. A: At., Mol., Opt. Phys. 1985, 31, 1695-1697.

(60) Nosé, S. A unified formulation of the constant temperature molecular dynamics methods. J. Chem. Phys. 1984, 81, 511-519.

(61) Jiang, J. Z.; Olsen, J. S.; Gerward, L.; Abdali, S.; Eckert, J.; Schlorke-de Boer, N.; Schultz, L.; Truckenbrodt, J.; Shi, P. X. Pressure effect on crystallization of $\mathrm{Fe}_{72} \mathrm{P}_{11} \mathrm{C}_{6} \mathrm{~A}_{15} \mathrm{~B}_{4} \mathrm{Ga}_{2}$ bulk metallic glass forming alloy. J. Appl. Phys. 2000, 87, 2664-2666.

(62) Jiang, J. Z.; Roseker, W.; Sikorski, M.; Cao, Q. P.; Xu, F. Pressure effect of glass transition temperature in $\mathrm{Zr}_{46.8} \mathrm{Ti}_{8.2} \mathrm{Cu}_{7.5} \mathrm{Ni}_{10} \mathrm{Be}_{27.5}$ bulk metallic glass. Appl. Phys. Lett. 2004, 84, 1871-1873.

(63) Yavari, A. R.; Moulec, A. L.; Inoue, A.; Nishiyama, N.; Lupu, N.; Matsubara, E.; Botta, W. J.; Vaughan, G.; Michiel, M. D.; Kvick, Å. Excess free volume in metallic glasses measured by X-ray diffraction. Acta Mater. 2005, 53, 1611-1619.

(64) Bednarcik, J.; Michalik, S.; Sikorski, M.; Curfs, C.; Wang, X. D.; Jiang, J. Z.; Franz, H. Thermal expansion of a La-based bulk metallic glass: insight from in situ high-energy $\mathrm{x}$-ray diffraction. J. Phys.: Condens. Matter 2011, 23, 254204.

(65) Mattern, N.; Stoica, M.; Vaughan, G.; Eckert, J. Thermal behaviour of $\mathrm{Pd}_{40} \mathrm{Cu}_{30} \mathrm{Ni}_{10} \mathrm{P}_{20}$ bulk metallic glass. Acta Mater. 2012, $60,517-524$

(66) Gangopadhyay, A. K.; Blodgett, M. E.; Johnson, M. L.; Vogt, A. J.; Mauro, N. A.; Kelton, K. F. Thermal expansion measurements by $\mathrm{x}-$ ray scattering and breakdown of Ehrenfest's relation in alloy liquids. Appl. Phys. Lett. 2014, 104, 191907.

(67) Ketov, S. V.; Chen, N.; Caron, A.; Inoue, A.; Louzguine-Luzgin, D. V. Structural features and high quasi-static strain rate sensitivity of $\mathrm{Au}_{49} \mathrm{Cu}_{26.9} \mathrm{Ag}_{5.5} \mathrm{Pd}_{2.3} \mathrm{Si}_{16.3}$ bulk metallic glass. Appl. Phys. Lett. 2012, $101,241905$.

(68) Eisenbart, M.; Klotz, U. E.; Busch, R.; Gallino, I. A colourimetric and microstructural study of the tarnishing of goldbased bulk metallic glasses. Corros. Sci. 2014, 85, 258-269.

(69) Shpyrko, O. G.; Streitel, R.; Balagurusamy, V. S. K.; Grigoriev, A. Y.; Deutsch, M.; Ocko, B. M.; Meron, M.; Lin, B.; Pershan, P. S. Surface crystallization in a liquid AuSi Alloy. Science 2006, 313, 7780.

(70) Shpyrko, O. G.; Streitel, R.; Balagurusamy, V. S. K.; Grigoriev, A. Y.; Deutsch, M.; Ocko, B. M.; Meron, M.; Lin, B.; Pershan, P. S. Crystalline surface phases of the liquid $\mathrm{Au}-\mathrm{Si}$ eutectic alloy. Phys. Rev. B: Condens. Matter Mater. Phys. 2007, 76, 245436.

(71) Mechler, S.; Yahel, E.; Pershan, P. S.; Meron, M.; Lin, B. Crystalline monolayer surface of liquid $\mathrm{Au}-\mathrm{Cu}-\mathrm{Si}-\mathrm{Ag}-\mathrm{Pd}$ : metallic glass former. Appl. Phys. Lett. 2011, 98, 251915.

(72) Henkelman, G.; Arnaldsson, A.; Jónsson, H. A fast and robust algorithm for Bader decomposition of charge density. Comput. Mater. Sci. 2006, 36, 354-360.

(73) Finney, J. L. Random packings and the structure of simple liquids. I. The geometry of random close packing. Proc. R. Soc. London, Ser. A 1970, 319, 479-493. 